\title{
Pengendalian Mobile Robot Non-Holonomic Berdasarkan Gestur Jari Menggunakan Template Matching
}

\author{
Ali Rizal Chaidir*, Dedy Wahyu Herdiyanto dan Guido Dias Kalandro \\ Jurusan Teknik Elektro, Fakultas Teknik, Universitas Jember, Jember, Jawa Timur, Indonesia \\ ${ }^{*}$ Corresponding author, e-mail: ali.rizal@unej.ac.id
}

\begin{abstract}
Abstrak-Pengendalian mobile robot non-holonomic berdasarkan gestur adalah suatu teknik untuk mengatur gerakan mobile robot non-holonomic menggunakan gestur jari, setiap gestur mewakili gerakan robot. Mobile robot dapat bergerak maju, mundur, belok kanan, dan belok kiri berdasarkan gestur jari. Tugas tersebut dapat dilakukan berdasarkan perintah operator. Dengan memanfaatkan perintah operator, pergerakan robot tidak tergantung pada lingkungan yang tetap. Salah satu teknik yang digunakan operator untuk mengendalikan robot adalah menggunakan sensor yang terpasang di tangan operator. Selain membutuhkan komponen sensor, penggunaan sensor membutuhkan perangkat keras tambahan untuk mengakuisisi data hasil pembacaan sensor. Penelitian ini menawarkan solusi lain untuk mengendalikan mobile robot non-holonomic, yaitu menggunakan kamera untuk mengenali gestur tangan operator robot. Setiap gestur disimpan dalam bentuk citra biner, kemudian setiap citra gestur yang tertangkap kamera dibandingkan dengan citra yang tersimpan sebelumnya menggunakan template matching. Sehingga pergerakan robot beroda non-holonomic bergerak berdasarkan gestur jari operator. Hasil dari penelitian ini menunjukkan kamera mampu mengenali gestur jari untuk memberikan perintah kepada robot. Gestur jari digunakan untuk memberikan perintah kepada robot agar bergerak maju, mundur, belok kanan dan kiri, dan berhenti, persentase keberhasilan dari pengujian tersebut adalah sebesar 95\%.
\end{abstract}

Kata Kunci : Gestur, Mobile robot dan Template matching

\begin{abstract}
Control of non-holonomic mobile robots based on gestures is a technique for controlling nonholonomic mobile robot movements using finger gestures. Mobile robots can move forward, backward, turn right, and turn left based on finger gestures. The task can be done based on the operator's command. One of the techniques used by operators to control robots is to use sensors installed in the operator's hands. In addition to requiring sensor components, the use of sensors requires additional hardware to acquire sensor readings. This research offers another solution for controlling non-holonomic mobile robots. The solution is to use a camera to recognize the robot operator's hand gestures. Each gesture is stored as a binary image, then each gesture captured by the camera is compared with the previously saved image using template matching, so that the movement of the non-holonomic wheeled robot moves based on the operator's finger gesture. The results of this study indicate the camera can recognize finger gestures to give commands to the robot. Finger gestures are used to give commands to the robot to move forward, backward, turn right and left, and stop, the percentage of success of the test is $95 \%$.
\end{abstract}

Keywords : Gesture, Mobile robot dan Template matching

\section{Pendahuluan}

Manusia membutuhkan teknologi untuk mempercepat dan mempermudah tercapainya suatu tujuan tertentu, robotika merupakan teknologi yang dapat membantu dan menggantikan manusia untuk melaksanakan tugasnya, terutama tugas-tugas yang berbahaya bagi manusia. Pada umumnya teknologi robotika diterapkan pada bidang pertanian [1], medis, dan industri [2]. Di bidang medis robot dapat dimanfaatkan untuk membantu dokter melakukan kegiatan pembedahan pasien [3] dan sebagai pembantu pasien disabilitas [4], di bidang pertanian robot dapat ditugaskan untuk melakukan penanaman [1], pemeliharaan atau pemeriksaan [5], dan pemanenan tanaman [6]. Sedangkan di industri, misalnya untuk manufacturing [7] robot dapat mempercepat proses produksi suatu barang.

Salah satu pekerjaan dasar dan umum yang dapat dilakukan robot adalah mengambil, memindah, dan meletakkan objek. Untuk melakukan itu, maka mobile robot harus memiliki 
kemampuan bergerak maju, mundur, berhenti, dan belok kanan serta kiri.

Beberapa jenis mobile robot diantaranya adalah mobile robot beroda holonomic dan non holonomic, sesuai dengan namanya robot beroda mampu berpindah tempat dari suatu tempat ke tempat lain di lingkungan tertentu, sedangkan robot lengan yang dilengkapi gripper dapat ditugaskan untuk mengambil, memindah dan meletakkan suatu objek dalam jangkauan robot lengan robot. Contoh penerapan robot tersebut adalah sebagai media pembelajaran dalam menulis [8], penjinak bom [9], robot bergerak menuju bom, mengambil, lalu membawa ke tempat yang lebih aman untuk dijinakkan.

Robot dapat bergerak secara autonomous atau bisa juga dibuat untuk mengikuti perintah operator. Dua cara tersebut dapat direalisasikan menggunakan mesin vision, dengan menggunakan mesin vision, robot dapat bergerak mengikuti jalur yang harus dilewati secara autonomous [10], dan mesin vision dapat juga digunakan untuk melihat gestur tangan operator untuk menentukan gerakan robot [11][12].

Keuntungan navigasi robot menggunakan perintah operator dibandingkan menggunakan sensor adalah robot relatif tidak memiliki ketergantungan pada lingkungannya, robot lebih banyak memiliki kebebasan gerakan, dan memiliki kecepatan yang lebih baik dalam bergerak dibandingkan menggunakan sistem kendali menggunakan tombol. Selain itu, mesin vision memiliki keuntungan yaitu tidak membutuhkan perangkat elektronika yang lebih banyak dibandingkan dengan sensor yang diletakkan pada tangan untuk membaca gestur [13], sehingga tangan operator tidak terganggu oleh perangkat sensor.

Algoritma pengenalan gestur yang digunakan adalah template matching. Template matching merupakan salah satu teknik untuk menyelesaikan masalah di bidang pengolahan citra, misalnya tentang tracking, dan recognition, termasuk dapat diterapkan untuk mengenali gestur. Salah satu kelebihannya adalah tidak memerlukan komputasi yang besar.

Pada penelitian ini mobile robot nonholonomic dapat dikendalikan berdasarkan gestur jari dengan memanfaatkan web cam untuk mengenali gestur operator robot. Gerakan robot beroda bergerak sesuai dengan gestur jari operator, yaitu bergerak maju, mundur, berhenti, dan belok kanan serta kiri.

\section{Metode Penelitian}

Robot yang digunkan adalah jenis mobile robot seperti yang ditunjukkan pada Gambar 1, robot tersebut terdiri dari robot mobile beroda dengan pergerakan non-holonomic, mobile robot beroda memiliki ukuran lebar $32 \mathrm{~cm}$, panjang 18 $\mathrm{cm}$, dan tinggi $15 \mathrm{~cm}$ dengan tipe $4 \mathrm{WD}$. Robot bergerak berdasarkan perintah operator yang berupa gestur jari dan tangan, gestur tersebut ditangkap oleh kamera, kamera yang digunakan adalah web cam A4tech. Hasil citra yang ditangkap oleh kamera kemudian akan dioleh di sebuah laptop dan kemudian dikirim ke sebuah kontroler untuk memberikan signal digital ke driver motor. Kontroler utama robot adalah board Arduino uno, dan driver motor yang digunakan untuk mengatur arah putaran roda robot menggunakan modul driver motor MC33886.

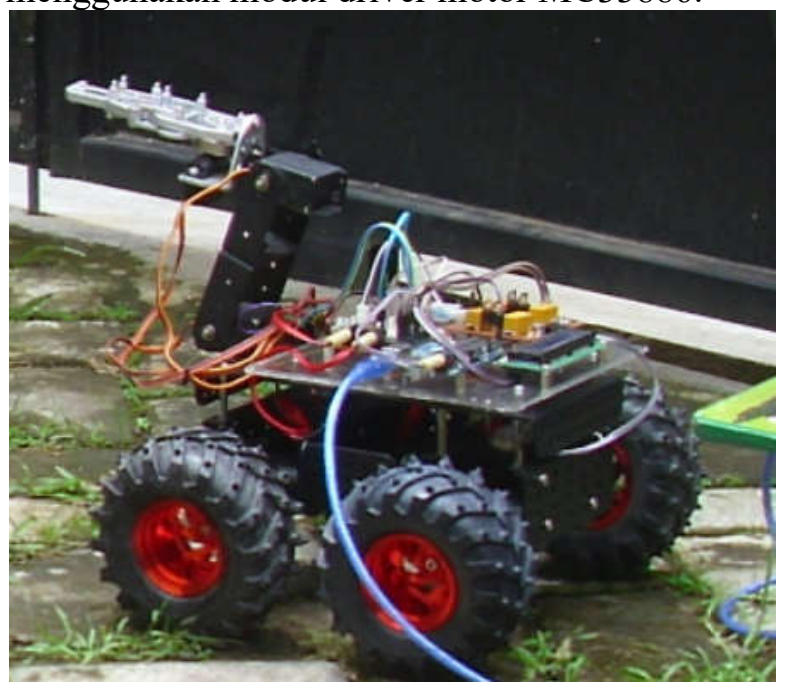

Gambar 1. Mobile robot non-holonomic

\subsection{Sistem Blok Diagram}

Sistem blok diagram secara keseluruhan pada penelitian ini dapat dilihat pada Gambar 2. Kamera yang digunakan adalah sebuah $\mathrm{Web} \mathrm{Cam}$ yang difungsikan untuk menangkap citra tangan dan jari operator, citra yang tertangkap oleh web cam adalah citra dengan format RGB. Hasil pembacaan citra tersebut kemudian dimasukkan ke sebuah algoritma yang dibuat di dalam komputer untuk mendapatkan parameter gestur jari operator untuk kemudian digunakan sebagai dasar untuk menggerakkan robot. Parameter yang diperoleh selanjutnya dikirim secara serial ke sebuah mikrokontroler dan kemudian mikrokontroler mengirim data ke system driver motor untuk menentukan gerakan mobile robot. 
Terdapat algoritma pengolahan citra untuk mendukung system yang ditunjukkan pada gambar 1, algoritma tersebut adalah algoritma untuk mengenali gestur jari. Algortima untuk mengenali gestur jari adalah sebuah algoritma yang digunakan untuk membedakan setiap bentuk lima jari operator, bentuk lima jari operator tersebut digunakan untuk menentukan gerakan mobile robot. Algoritma tersebut digunakan setelah proses konversi citra dilakukan, yaitu konversi citra dari RGB ke Biner.

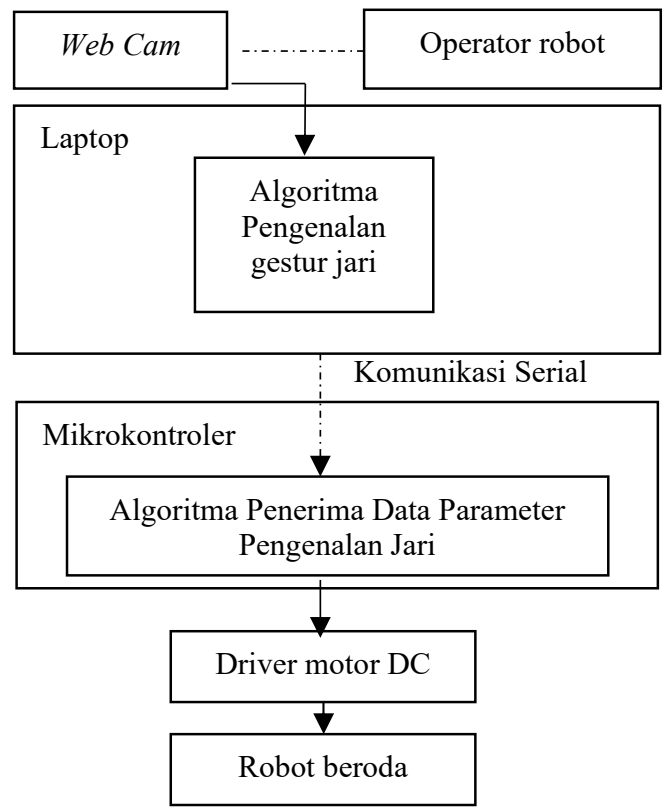

Gambar 2. Blok diagram sistem

\subsection{Konversi citra RGB menjadi citra biner}

Citra biner digunakan pada algoritma pengenalan gestur jari. Untuk menghasilkan citra biner, format citra RGB dikonversi menjadi citra YCbCr terlebih dahulu. Gambar 3 menunjukkan langkah untuk menghasilkan citra biner, citra tersebut dianggap lebih baik dalam pengenalan kulit daripada citra RGB dan memiliki tumpang tindih yang kecil antara skin color dan non-skin color dalam berbagai kondisi pencahayaan [14]. Disetiap citra dimungkinkan terdapat derau yang berbentuk bitnik-bintik, untuk mengurangi derau tersebut tahap selanjutnya adalah melakukan filterisasi menggunakan filter median, filter median mampu untuk menghilangkan bitnikbintik pada sebuah citra [15]. Tahap terakhir untuk mendapatkan citra biner atau memisahkan latar belakang dan latar depat citra adalah melakukan proses thresholding menggunakan Persamaan (1), nilai ambang diatur untuk memisahkan citra latar belakang dan latar depan, citra latar depan direpresentasikan dengan nilai piksel disetiap parameter Ycbcr dengan nilai 255 (berwarna putih), sedangkan warna piksel citra latar belakang adalah berwarna hitam.

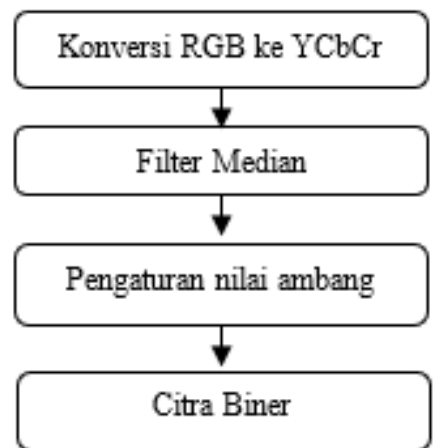

Gambar 3. Tahapan untuk menghasilkan citra biner

$G(x, y)=\left\{\begin{aligned} 1 \text { if } & T y \max \geq \mathrm{Y}(x, y) \geq T y \min \cup \\ & T c r \max \geq Y(x, y) \geq T c r \text { min } \cup \\ & T c b \max \geq Y(x, y) \geq T c b \min \\ 0 & \text { if } \text { else }\end{aligned}\right.$

dimana $\mathrm{G}(\mathrm{x}, \mathrm{y})$ adalah image biner, $\mathrm{Y}(\mathrm{x}, \mathrm{y})$ adalah image $\mathrm{YCrCb}$, Tymax dan Tymin menyatakan nilai threshold maksimal dan minimal komponen Y, Tcrmax dan Tcrmin menyatakan nilai threshold maksimal dan minimal komponen cr, Tcbmax dan Tcbmin menyatakan nilai threshold maksimal dan minimal komponen cb.

\subsection{Pengenalan Gestur Jari}

Gerakan robot beroda maju, belok kanan dan kiri, mundur, dan berhenti didasarkan oleh gestur jari operator. Tahapan pengenalan gestur jari ditunjukkan pada gambar 4, pengenalan gestur jari diawali dengan menerapkan algoritma deteksi tepi pada citra biner yang telah dihasilkan sebelumnya, algoritma deteksi tepi adalah salah satu algoritma yang dapat mendeteksi tepi objek pada sebuah citra [16]. Metode deteksi tepi yang digunakan adalah algoritma canny, algoritma tersebut adalah salah satu algoritma yang cukup optimal untuk melakukan deteksi tepi pada sebuah citra [16]. Hasil citra dari penerapan algoritma canny selanjutnya dilakukan proses pengambilan area yang dibutuhkan saja yaitu menggunakan teknik ROI secara otomatis. Citra yang menunjukkan area yang dibutuhkan saja kemudian disimpan sebagai template untuk dibandingkan dengan citra 
yang tertangkap webcam pada saat operator memberikan perintah pada mobile robot.

Sesuai dengan jumlah jenis gerakan robot, yaitu maju, mundur, belok kanan dan kiri, serta berhenti, maka ada lima citra yang digunakan sebagai template, setiap citra yang tertangkap dibandingkan dengan template citra yang sebelumnya tersimpan, untuk membandingkan dua citra menggunakan persamaan (2) yaitu metode template matching, template marching merupakan salah satu teknik untuk menyelesaikan masalah di bidang pengolahan citra, misalnya tentang tracking, dan recognition, termasuk dapat diterapkan untuk mengenali gestur. Kesamaan dua citra ditunjukkan oleh nilai korelasi yang dihasilkan, setiap template citra dibandingkan dengan citra yang ditangkap webcam, nilai korelasi tertinggi menunjukkan kesamaan citra dan keputusan tersebut dikirim secara serial ke mikrokontroler.

$$
\text { cor }=\frac{\sum_{i=0}^{N-1}\left(x_{i}-\bar{x}\right) \cdot\left(y_{i}-\bar{y}\right)}{\sqrt{\sum_{i=0}^{N-1}\left(x_{i}-\bar{x}\right)^{2} \cdot \sum_{i=0}^{N-1}\left(y_{i}-\bar{y}\right)^{2}}}
$$

Dimana $x$ adalah citra sebagai template, $\bar{x}$ adalah rata-rata dari citra sebagai template, $y$ adalah sumber citra, $\bar{y}$ adalah rata-rata dari sumber citra, dan $N$ adalah ukuran dari citra sebagai template.

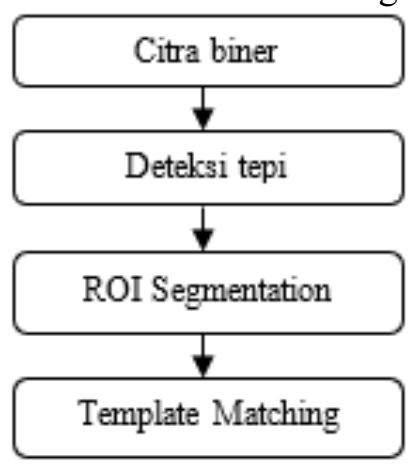

Gambar 4. Tahapan pengenalan gestur jari

\subsection{Rangkaian Elektronika}

Komponen utama yang digunakan (gambar 5) adalah Arduino sebagai board mikrokontroler untuk menerima data dan memberikan sinyal digital High atau Low untuk dikirim ke modul driver motor MC33886 yang selanjutnya mengendalikan arah putaran motor dc robot beroda.

Tugas utama dari mikrokontroler yang digunakan adalah menerima data secara serial dan mengirimkannya modul MC33886. Pin 10 sampai
13 pada board Arduino dihubungkan ke pin input 1 sampai 4 pada modul driver motor MC33886 secara berturut-turut.

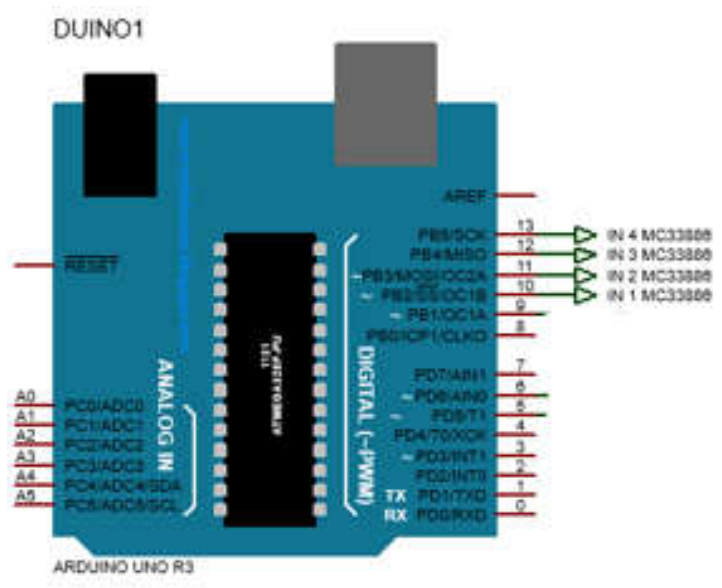

Gambar 5. Rangkaian Elektronika untuk Mengendalikan Motor

\subsection{Metode Pengujian dan Analisa}

Pengujian dilakukan pada rangkaian driver motor, algoritma pengenalan gestur, dan pengujian terhadap sistem keseluruhan.

Respon rangkaian driver motor diuji berdasarkan input digital yang diberikan pada setiap pin input modul, selain itu algoritma pengenalan gesture juga diuji, yaitu dengan tujuan untuk mengetahui kombinasi yang memiliki tingkat kesalahan terkecil dan selanjutnya digunakan untuk mengendalikan robot.

Tahap terakhir adalah melakukan pengujian sistem keseluruhan, pengujian dilakukan menggunakan kombinasi gestur yang sebelumnya telah ditentukan. Pengujian dilakukan untuk mengetahui respon robot terhadap gestur, yaitu dengan menggunakan sebuah jalur untuk diikuti robot berdasarkan perintah operator. Sistem keseluruhan dikatakan berhasil ketika robot dapat bergerak sampai titik akhir sesuai dengan jalur robot, pengujian ini dilakukan sebanyak 20 kali. Setiap pengujian hanya dilakukan oleh satu operator.

\section{Hasil dan Pembahasan}

Pergerakan robot ditentukan dengan gestur jari. Kinerja robot diukur berdasarkan keberhasilan robot mengikuti gestur jari operator untuk melakukan tugas yang diperintahkan operator. Pengujian dilakukan oleh satu orang operator, setiap kombinasi gestur yang digunakan 
dicatat dan kemudian dianalisa dan ditentukan untuk mengendalikan robot.

\subsection{Hasil Pengujian Driver Motor}

Driver motor adalah salah satu rangkaian terpenting untuk menggerakkan robot beroda. Empat pin output Arduino yang digunakan mampu memberikan sinyal digital untuk menggerakkan robot. Hasil pengujian driver motor dapat dilihat pada Table 1 .

\begin{tabular}{|c|c|c|c|c|}
\hline \multicolumn{4}{|c|}{$\begin{array}{l}\text { Nilai Pin } \\
\text { Arduino }\end{array}$} & \multirow{2}{*}{$\begin{array}{c}\text { Gerakan } \\
\text { Robot }\end{array}$} \\
\hline 10 & 11 & 12 & 13 & \\
\hline 1 & 0 & 1 & 0 & Maju \\
\hline 0 & 1 & 0 & 1 & Mundur \\
\hline 1 & 0 & 0 & 1 & $\begin{array}{l}\text { Belok } \\
\text { Kanan }\end{array}$ \\
\hline 0 & 1 & 1 & 0 & $\begin{array}{r}\text { Belok } \\
\text { Kiri }\end{array}$ \\
\hline 0 & 0 & 0 & 0 & Berhenti \\
\hline
\end{tabular}

\subsection{Hasil Pengujian Gerakan Robot Beroda Berdasarkan Gestur Jari}

Pengukuran kinerja robot beroda dilihat berdasarkan kesesuaian pergerakan robot beroda dengan gestur jari operator, table 2 sampai 4 menunjukkan hasil pengujian pergerakan robot sesuai dengan kombinasi gestur jari yang digunakan.

Table 2. Hasil Pengujian Gestur Jari Ke 1

\begin{tabular}{cccc}
\hline Template & Gestur & $\begin{array}{c}\text { Gerakan } \\
\text { Robot yang } \\
\text { Diinginkan }\end{array}$ & $\begin{array}{c}\text { Gerakan } \\
\text { Robot dari } \\
\text { Pengujian }\end{array}$ \\
Jangan & Maju & Maju \\
\hline
\end{tabular}

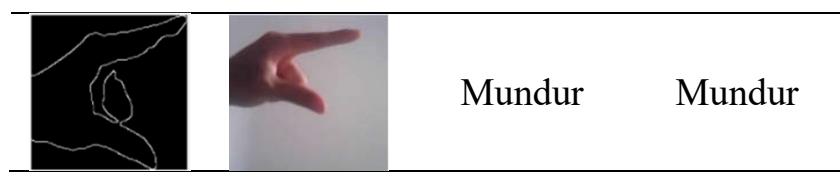

Table 3. Hasil Pengujian Gestur Jari Ke 2

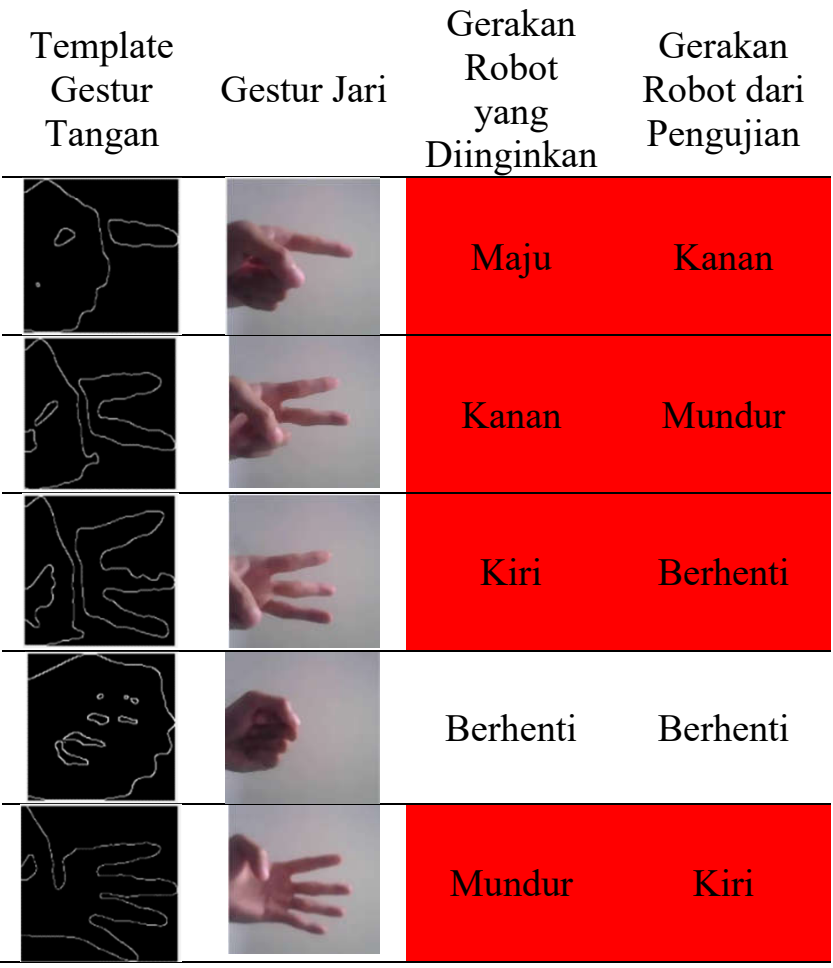

Table 4. Hasil Pengujian Gestur Jari Ke 3

Template
$\begin{gathered}\text { Gerakan } \\ \text { Robot } \\ \text { yang } \\ \text { Diinginkan }\end{gathered}$ $\begin{gathered}\begin{array}{c}\text { Gerakan } \\ \text { Robot dari } \\ \text { Pengujian }\end{array} \\ \text { Kangan }\end{gathered}$



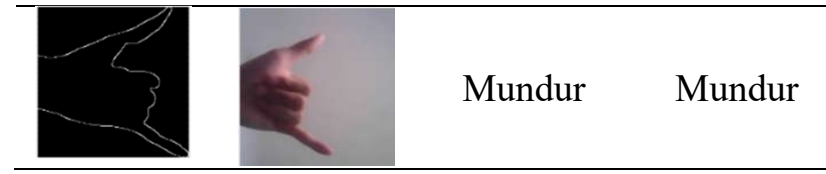

Table 2 dan 3 menunjukkan kesalahan pembacaan gestur jari yang diberikan terhadap template gestur yang sebelumnya telah disimpan (warna merah), kombinasi gestur table 2 dan 3 memiliki kemiripan disetiap gesturnya. Berbeda dengan kombinasi gestur table 4, kombinasi gestur jari 4 memiliki kemiripan yang lebih kecil dibandingkan kombinasi gestur table 2 dan 3 . Berdasarkan hasil tersebut maka kombinasi gestur jari pada table 4 digunakan untuk memberikan perintah kepada robot beroda, karena memiliki akurasi yang lebih besar dibandingkan dengan hasil pengujian pada tabel 2 dan 3 .

Selanjutnya adalah melakukan pengujian terhadap robot, robot bergerak berdasarkan gestur yang diberikan operator, skenario pengujian ditunjukkan pada Gambar 6 dan hasil pengujian ditunjukkan pada table 5 .

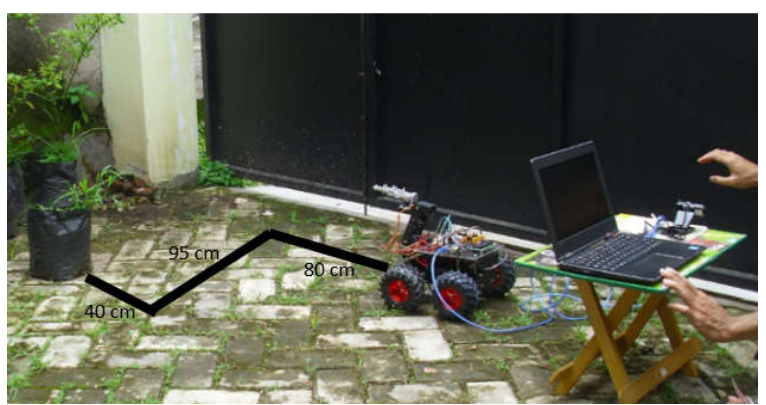

Gambar 6. Jalur pengujian gerakan robot

Table 5. Hasil Pengujian Kombinasi Gestur Jari Terhadap Robot

\begin{tabular}{ccc}
\hline Pengujian & $\begin{array}{c}\text { Waktu tempuh } \\
\text { (detik) }\end{array}$ & Keberhasilan \\
\hline 1 & 21 & Berhasil \\
\hline 2 & 17 & Berhasil \\
\hline 3 & - & Gagal \\
\hline 4 & 20 & Berhasil \\
\hline 5 & 25 & Berhasil \\
\hline 6 & 17 & Berhasil \\
\hline 7 & 17 & Berhasil \\
\hline 8 & 17 & Berhasil \\
\hline 9 & 16 & Berhasil \\
\hline 10 & 17 & Berhasil \\
\hline 11 & 30 & Berhasil \\
\hline 12 & 14 & Berhasil \\
\hline 13 & 17 & Berhasil \\
\hline
\end{tabular}

\begin{tabular}{lll}
\hline 14 & 15 & Berhasil \\
\hline 15 & 25 & Berhasil \\
\hline 16 & 20 & Berhasil \\
\hline 17 & 10 & Berhasil \\
\hline 18 & 10 & Berhasil \\
\hline 19 & 18 & Berhasil \\
\hline 20 & 11 & Berhasil \\
\hline
\end{tabular}

Tabel 5 menunjukaan hasi pengujian pergerakan robot, tingkat keberhasil yang didapat adalah $95 \%$, dari 20 pengujian pada pengujian ke 3 robot gagal mencapai titik akhir lintasan, robot tidak dapat dikendalikan untuk mencapai titik akhir lintasan. Selain itu, dari tabel tersebut juga menunjukkan bahwa setiap pengujian memiliki waktu tempuh yang berbeda, waktu tempuh yang sering terjadi adalah 17 detik, terlama adalah 30 detik, tercepat adalah 10 detik, rata-rata waktu tempuh yang didapat adalah 17,7 detik, dan standart deviasi yang diperoleh sebesar 5,10. Sedangkan jika dilihat dari perubahan waktu tempuh yang terjadi mulai dari pengujian pertama sampai trakhir maka dapat dilihat bahwa nilai tersebut menjadi semakin kecil.

\section{Kesimpulan}

Pengendalian mobile robot non-holonomic menggunakan gestur jari telah dilakukan, dari pengujian yang telah dilakukan terlihat bahwa gestur jari cukup mampu dikenali oleh algoritma pemrograman yang telah dibuat. Keberhasilan robot untuk bernavigasi berdasarkan gestur adalah sebesar 95\%. Diperlukan kebiasaan untuk menggunakan gestur dalam mengendalikan robot, hal ini dapat dilihat dari tabel hasil pengujian robot beroda dalam bernavigasi.

\section{Daftar Pustaka}

[1] U. Masood Ul, U. Mukhtar, I. Jamshed, "Towards autonomy in agriculture: design and prototyping of a robotic vehicle with seed selector," International Conference on Robotics and Artificial Intelligence (ICRAI), pp 37 - 44, 2016.

[2] B. Siciliano, O. Khatib, "Springer Handbool of Robotics," Springer, 2008.

[3] F. Sakura, dkk, "Development of virtual training system for endoscopic surgery," 2018 International Conference on Information and Communication 
Technology Robotics (ICT-ROBOT), pp $1-4,2018$.

[4] G. Xiang, S. Lei, “The design of robotics wheelchair control system based on hand gesture control for the disabled," 2017 International Conference on Robotics and Automation Sciences, pp 30 - 34, 2017.

[5] C. Keun Ha, dkk, "Vision based guidance line extraction for autonomous weed control robot in paddy field," IEEE Conference on Robotics and Biomimetics, pp $831-836,2015$.

[6] Y. Hiroaki, dkk, "Development of an autonomous tomato harvesting robot with rotational plucking gripper," International Conference on Intelligent Robots and System (IROS), pp 652 - 657, 2016.

[7] P. Sakari, K. Jari, M. jari, "Simulation and programming experiences of collaborative robots for small-scale manufacturing," $20182^{\text {nd }}$ International Symposium on small-scale Intelligent Manufacturing System (SIMS), pp 1- 4, 2018.

[8] Rendyansyah, P. Aditya, "Simulasi Robot Manipulator 4 DOF Sebagai Pembelajaran Dalam Kasus Robot Menulis Huruf", Jurnal Nasional Teknik Elektro, Vol. 5, No. 3, pp. 339-349, 2016.

[9] M. Abdul Kadir Bin, H. Mohammad Busayeed, H. Md. Ahsanul, "Bomb disposal Robot," International Conference on Innovations in Sciences, Engineering and Technology (ICISET), pp 1-5, 2016.

[10] C. Ali Rizal, A. Khairul, R. Gamma Aditya, "Lane Tracking pada Robot Beroda Holonomic Menggunakan Pengolahan Citra", Jurnal Elkomika, Vol. 8, No. 1, pp. 69-79, 2020.
[11] C. Ali Rizal, M. Wahyu, K. Guido Dias, "Pengenalan Gestur Jari Menggunakan Pengolahan Citra untuk Mengendalikan Joint pada Base Robot Lengan", Jurnal Rekayasa Elektrika, Vol. 14, No. 3, pp. 174-180, 2018.

[12] C. Ali Rizal, S. Alfredo Bayu, K. Guido Dias, "Design of a gripping imitator robotic arm for taking an object," International Conference on Information and Communication Technology (ICoICT), pp. 1 - 5, 2016

[13] P. Alexandru, dkk, "Remote control of a robotic platform based on hand gesture recognition," The $6^{\text {th }}$ IEEE International Conference on E-Health and Bioengineering - EHB, pp 643 - 646, 2017

[14] W. Wei, P. Jing, "Hand segmentation using skin color and background information," International Conference on Machine Learning and Cybernetics, Vol. 4., pp. 1487 - 1492, 2012.

[15] E. Ramaraj, A. Senthil Rajan, "Median filter using open multiprocessing in agriculture," IEEE $10^{\text {th }}$ International conference on signal processing proceedings, pp. 42-45, 2010.

[16] G. Christos, dkk, "Real-time canny edge detection parallel implementation for FPGAs" International Conference on Eelectronics, Circuits and System, pp 499 $-502,2010$. 